\title{
PROPOSAL OF DEVICE FOR MONITORING OF EDUCATIONAL MACHINE TOOLS
}

\author{
Miroslav Císar', Ivan Kuric', Nadežda Čuboňová', Štefan Vlček ${ }^{1}$ \\ 1 Faculty of Mechanical Engineering, University of Žilina, Univerzitna 1, 010 26, Žilina, Slovakia, e-mail: miroslav. \\ cisar@fstroj.uniza.sk, ivan.kuric@fstroj.uniza.sk,nadezda.cubonova@fstroj.uniza.sk
}

Received: 2016.07.04

Accepted: 2016.08.05 Published: 2016.09.01

\begin{abstract}
Maintaining machinery in conditions capable of production requires certain level of maintenance which should be planned in order to avoid unnecessary downtiqmes. Technical diagnostics and monitoring provides data necessary for effective targeting, planning, and optimizing maintenance actions. This article describes a proposal of a system designed for monitoring various parameters on educational machine tools of EMCO Concept series, which are widely used at schools and universities and therefore, relatively easily accessible for research without any issues regarding confidentiality, common in industrial applications. The article describes a situation for which the device was designed, measured parameters, sensors its implementation and testing.
\end{abstract}

Keywords: monitoring, prototype, machine tool, diagnostics.

\section{INTRODUCTION}

Reliability and accessibility of machinery are some of its most important parameters in a view of sustainable production. Machine tools as elements critical for production facilities requires certain level of maintenance in order to keep it in condition that assures production in desired quality. On the other hand, maintenance action almost always requires some downtime or even interruption of production. There are several approaches to maintenance planning, which allows to reduce undesirable impacts of machine tool downtime. Probably the most progressive methods use prediction based on diagnostics and monitoring, which provide necessary information about the current and previous state of the machine tool and its estimated development [1].

Some of current machine tools are equipped with self-diagnostic and self-monitoring capabilities or it is possible to implement it by modifying and adding various kinds of procedures, subroutines and subprograms to its control system. However, such modifications are not able to observe all physical parameters that can be useful for real time diagnosing and prognosing of machine tool condition. Therefore, we decided to design a prototype of a simple monitoring apparatus for monitoring various parameters of a machine tool and its environment that will be able to monitor, store and evaluate such parameters in real time. The collected data can be later analyzed in order to reveal, quantify, and spot correlations of machine tool condition, its performance and parameters that can be relatively easily monitored $[1,2]$.

\section{MONITORED MACHINE}

Monitoring of machine tools is not a totally new idea, most of current control systems are capable of logging its system variables or use free inputs of PLC that controls machine to connect sensors. Such a solution requires certain amount of knowledge about a specific machine tool and such solution can void warranty. Simpler machines or machines with non-common concep- 

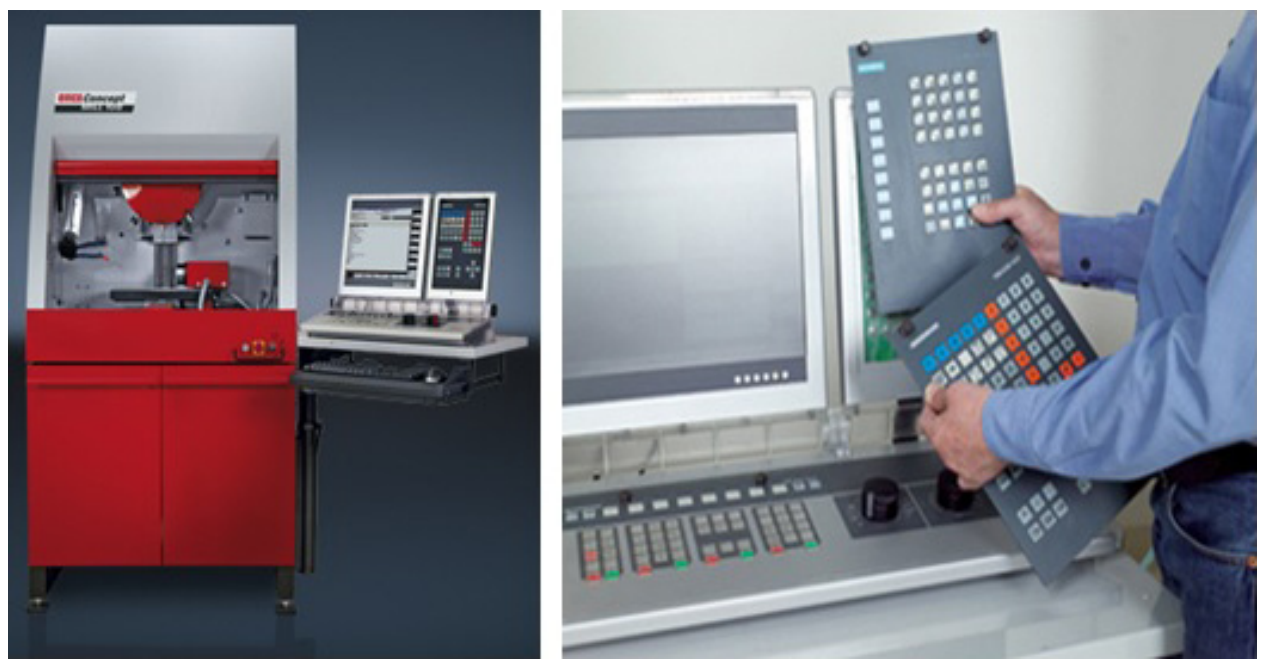

Fig. 1. Emco Concept Mill 105 with system of interchangeable control panels [3]

tion of control system structure such as machines of Emco Concept series, designed for industrial training, make implementation of monitoring using capabilities of control system even more difficult $[3,4,5]$.

Prototype of monitoring device is designed to be used on Emco Concept machines and it is currently in testing on Emco Concept Mill 105 (Fig. 1 ), which is used for training machine tool operating during lessons. Emco Concept machines are characteristic by its interchangeable control system which allows controlling one machine with multiple commercially available control systems. The machine is controlled via computer with windows operating system running WinNC software that manages switching between individual control systems. Physical control elements of interchangeable is done by changing parts two parts of control panel as shown on the Figure $1[4,5]$.

Control system is then spited to two parts: PLC that actually mechanical part, and computer running instance of simulated control system. Communication between these two parts is done thru standard Ethernet, therefor connection of these machines to internet is rather rare. Such arrangement (Fig. 2) makes monitoring using standard inputs and interface of machine tool control system virtually impossible $[3,4,6]$.

The features that make routines common for machine tool monitoring complicated also allows to use different approach to collect and log technological data thru scanning memory allocated by program that controls a machine tool. In order to do that we created special software designed to silently collect data about machine tool usage and its operating param- eters. Current version of this software - MT monitor (Fig. 3) is capable of monitoring the following information:

- $\mathrm{X}, \mathrm{Y}$, and $\mathrm{Z}$ coordinates of tool ( $\mathrm{X}$ and $\mathrm{Z}$ for lathes),

- actual feed rate and direction of movement,

- actual spindle speed and direction of its rotation.

The software also stores information about machine tool for its identification (model, serial number, location, etc.). User interface is accessible thru an icon in notification area. Graphical user interface is relatively simple and it serves primarily for initial setup and debugging and in most of time it is hidden. The collected data are stored in local instance of database and it can be exported in order to be analyzed together with information obtained by various diagnostic mea-

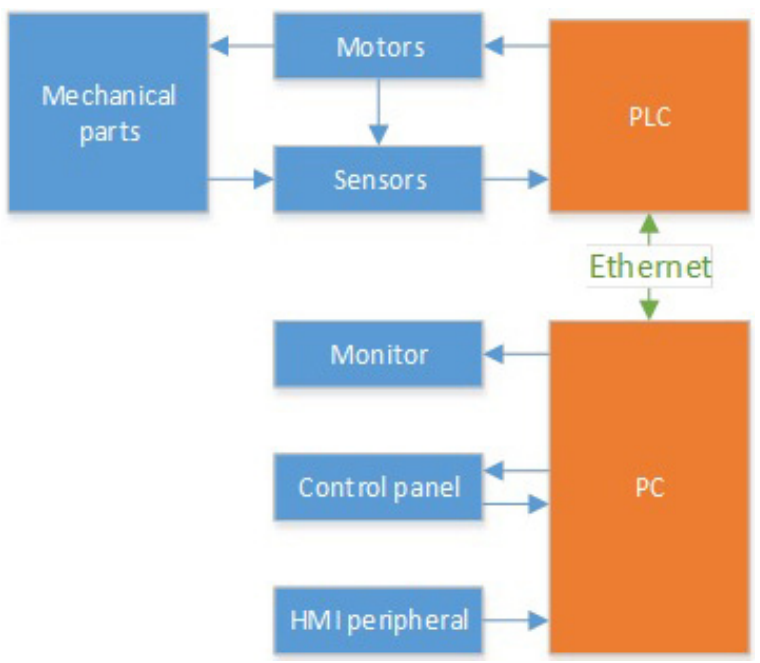

Fig. 2. Block structure of Emco Concept machine 


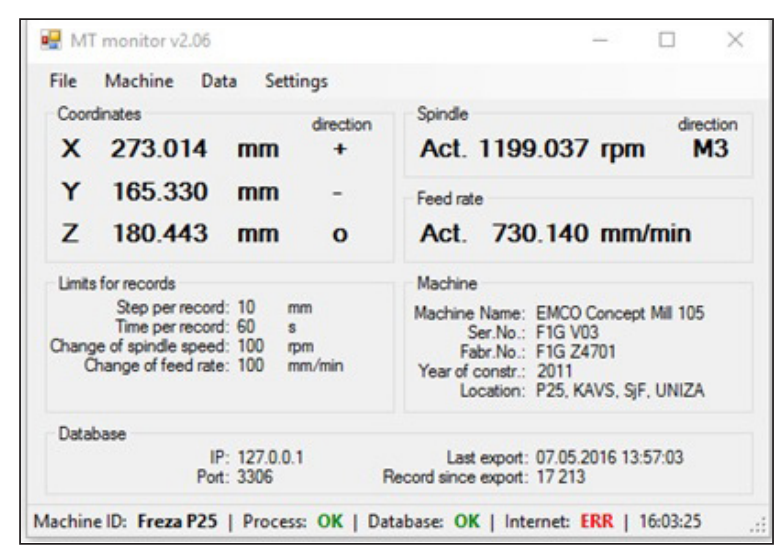

Fig. 3. Monitoring software MT monitor v.2.06

surements. Such analysis is done in order to find correlations between level machine tool usage, its precision, and other parameters. Long term monitoring and logging of such data is also important part of establishing trends of condition development useful for implementation of proactive maintenance based on predictions [11].

\section{DESIGN OF THE MONITORING DEVICE PROTOTYPE}

The possibilities of collecting data from system memory, described in the above chapter, is quite limited as we have no access to data that a simulated control system cannot show. Therefore, we decided to design and create a prototype device that would allow us to monitor parameters usable for diagnosing and monitoring of machine tool condition and performance.

Design of the described prototype of monitoring system is focused to test possibilities and limits of selected sensors, to offer necessary amount of data, and to keep costs in a reasonable range in order to simplify deployment of such device to more machines and thus increase amount of required information. Special devices capable of measuring physical quantities are usually quite costly and thus unsuitable for our application. Connecting sensors directly to computer also usually requires special hardware cards with $\mathrm{A} / \mathrm{D}$ converters.

In order to make data gathering as simple as possible, we decided to use Arduino UNO board, a microcontroller board based on the ATmega328. It has 14 digital input/output ports, 6 analog inputs, a $16 \mathrm{MHz}$ crystal oscillator, a USB connection, a power jack, an ICSP header. The Arduino platform is widely used, it supports plenty of various sensors with well documented behavior and ready to use libraries. When the board is connected to a computer via USB it uses emulated serial port that makes communication with board easily available. Programming the board can be done in $\mathrm{C}$ or $\mathrm{C}++$ language using Arduino IDE. There are also various replicas with virtually same hardware that are even cheaper than already easily accessible original boards. The board is small enough to be safely placed in appropriate place in machine tool casing without negative impact to machine tool performance.

For a first start we decided to monitor vibrations and temperatures, as such information is useful for diagnostics and we are able to verify if sensors are working properly using measurement devices available at our laboratories.

\section{MONITORING OF VIBRATIONS}

Measurement of vibrations or vibrodiagnostics is a versatile method that can reveal various errors in machine tool. It can also identify potentially harmful vibrations from environment which are able to negatively affect the machining process. Vibrations are natural accompaniment of movement of mechanical parts as a result of forces and tensions. The analysis of vibrations is beneficial especially for rotating parts such as spindles, bearings, and gears. Characteristics such as frequencies, amplitudes of signal and its components reflect internal processes of examined object, interactions between its parts and its condition as well as relations of such a device to environment. Each device has its own characteristic individual characteristics of vibrations that are developing during time according to its condition, similar to the case shown in Figure 4 [1].

The vibrations are an unavoidable part of normal function of devices to some extent. However,

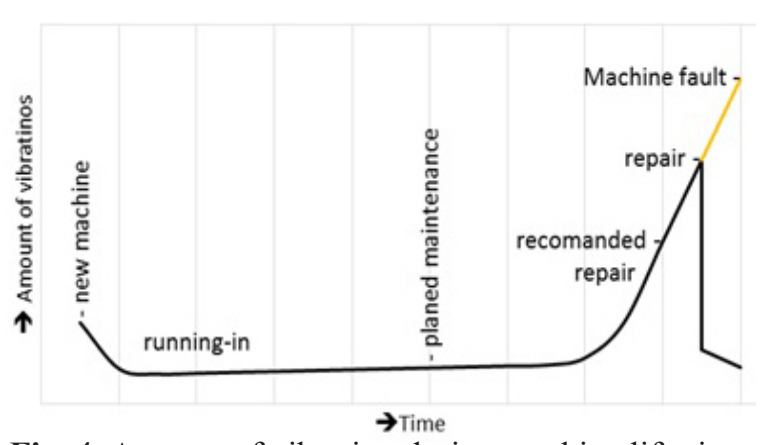

Fig. 4. Amount of vibration during machine life-time 


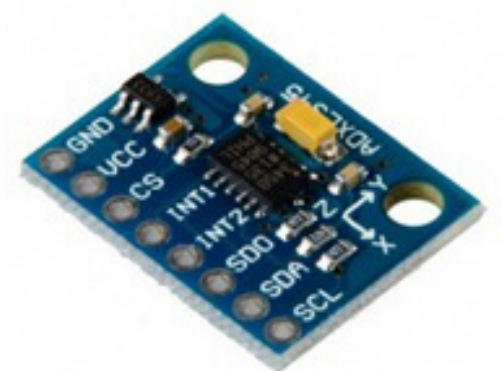

Fig. 5. 3-axis accelerometer ADXL345

excessive vibrations can lead to wear (or it can be a sign of wear), fatigue damage and deterioration of environment and device itself. Therefore, one of the main tasks is to determine what amount of vibration is in normal acceptable limits [1].

In order to monitor vibrations on our machine we selected small MEMS type accelerometer ADXL345 (Fig. 5) which is fully compatible with Arduino board used as an interface. Digital output data is accessible through either a SPI (3- or 4-wire) or I2C digital interface. According to datasheet it is reliable up to acceleration of $\pm 16 \mathrm{~g}$ [7].

We connected the accelerometer to a board with 4-wire SPI as it is the fastest available communication interface. In order to validate applicability and reliability of sensor we created a program that sends data from accelerometer to a computer thru a serial port. For initial test on a computer we used two programs. The first one is Realterm - a terminal program specially designed for capturing data streams, to save received data to text file in order to analyze it. The second software used is kst - fast multiplatform plotting and viewing designed to work with large datasets and capable of FFT analysis. The sources of controlled vibrations for the tests was a loudspeaker and sa mall lathe - Emco Concept Turn 55. Comparison of FFT analyzed data measured with ADXL345 and Renishaw XL-80 is shown in Figure 6. Insignificant deviation of frequencies measured by accelerometer and laser interferometer are probably caused by considerable difference of weights of measuring elements. We also performed tests of acceleration with a robot Fanuc LR Mate 200iC. Measured data was compared with dynamic measurements using laser interferometer Renishaw XL-80 and captures of which was also imported to kst in order to keep data analysis consistent. In case of robot we also compared the measured data with results of simulations and analysis of robot movement $[9,10]$.

The deviation of real spindle speed from the spindle speed shown and set in control system of lathe have manifested. The first assumption was that sensor failed but then the results of measurement with laser interferometer bring same data. The control measurement with speedometer revealed failure of lathe which is currently examined.

Placement and mounting of accelerometer on a machine tool is not a trivial task. In this case it was done by strong neodymium magnet fitted to board of accelerometer by screws. Nedymium magnet provides more than sufficient force to mounting necessary to perform measurements. After selecting a suitable connector and finishing a sensor testing, the accelerometer will be placed together with a magnet or magnets in machined aluminum case and encapsulated with epoxy resin in order to protect board against impact of swarf, coolants, and other environmental factor typical for machine tool workspace [11].

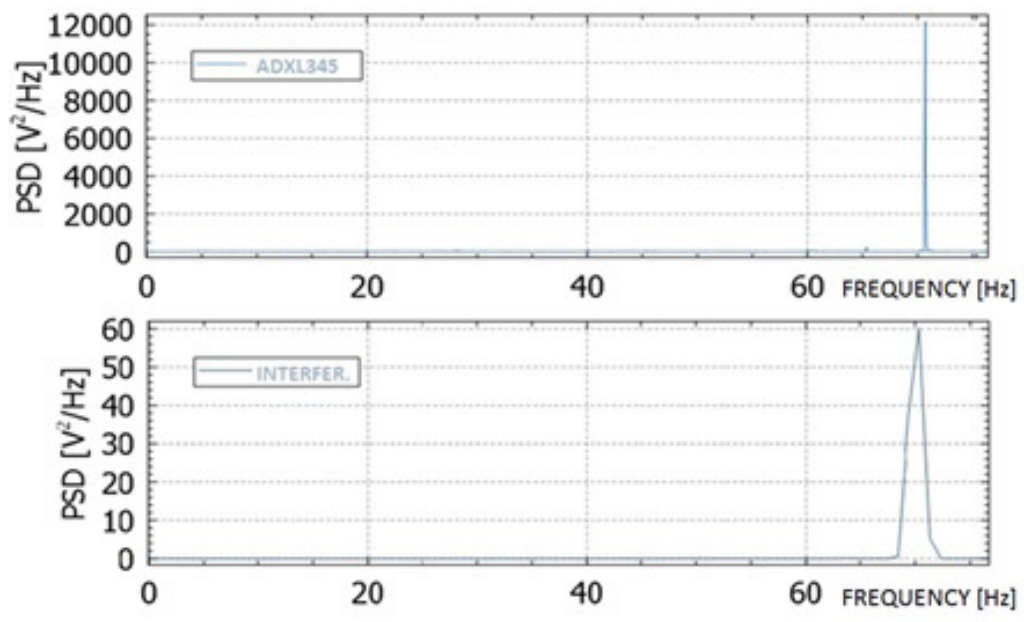

Fig. 6. Comparison of vibrations measured by ADXL345 (top) and Renishaw XL-80 (bottom) 

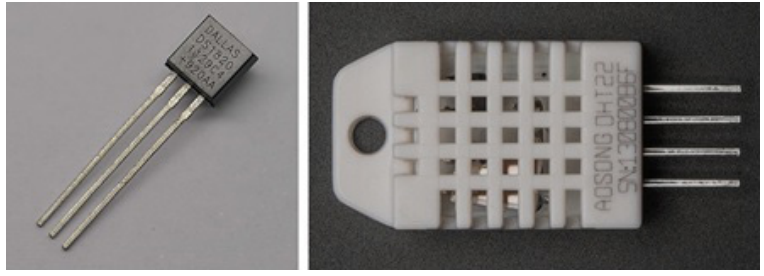

Fig. 7. DS1820 (left) and DHT33 (right)

\section{MONITORING TEMPERATURES}

The second parameter chosen to be monitored was temperature. Thermodiagnostics and especially thermography, as its part, is a fast and strong method of diagnostics able to reveal various faults and errors of machine tools. Thermography in general gives fast inspection rates, high level of security as an operator does not have to be exposed to a risk of injury, outputs are usually relatively easy to interpret. Professional tools for thermography are relatively expansive in comparison with other methods, such as vibrodiagnostics or tribodiagnostics $[1,2]$.

Sadly, the thermography is too complicated and expansive to be easily implemented in our monitoring system. The thermal image, as a result of thermography is actually a matrix of temperatures in space displayed in a form of a picture containing thermal fields. Knowing that we can get similar results by placing multiple temperature sensors to appropriate nodes of machine tool such as case stepper motors, feed mechanisms, bearings of a spindle, and so on. The measurement of ambient temperature can be useful in order to include the effects of environment. Strategically placed thermal sensor can reveal increase in temperature which as result of increased friction, excessive load, insufficient lubrication, or increased electrical current.
Thermal sensor Dallas DS1820 and digital thermal and humidity sensor DHT22 was selected for implementation of thermal measurements, both are shown in Figure 7.

The DS1820 uses 1-Wire ${ }^{\mathrm{TM}}$ for communication so it requires one digital pin in order to connect it to Arduino board. It is capable of measiring temperature between $-55^{\circ} \mathrm{C}$ to $125^{\circ} \mathrm{C}$ with $0.5^{\circ} \mathrm{C}$ increments, so the range and precision is more than sufficient to detect possible defects of machine.

The DHT22 is digital temperature and humidity sensor that uses a capacitive humidity sensor and a thermistor to measure the surrounding air. The range of measurement is from $-40^{\circ} \mathrm{C}$ to $80^{\circ} \mathrm{C}$ with $\pm 0.5^{\circ} \mathrm{C}$ accuracy for temperature and $0 \div 100 \%$ humidity with $2-5 \%$ accuracy. Readings can be done once every two seconds.

We designed case Figure 8 to enclose DS1820 in order to protect it and to improve its performance by maximizing the surface of contact. The cases will be made of copper or brass in order to keep because of its thermal conductivity. Mounting is designed using two $8 \mathrm{~mm}$ neodymium magnets fitted into circular pockets and held by bending edge of pocket to inside, the surface of magnets must not stick out of case surface and the thermal grease should be applied to inside of pocket before. The thermal grease should be also used to fit thermal sensor to a hole drilled to body of case and it can be also used to improve thermal conductivity between surfaces case and measured surface. Cable and necessary resistor should be soldered to sensor before connecting and it should be sealed inside using epoxy resin. The surface of sensor case that is not in contact with machine nodes should be covered with
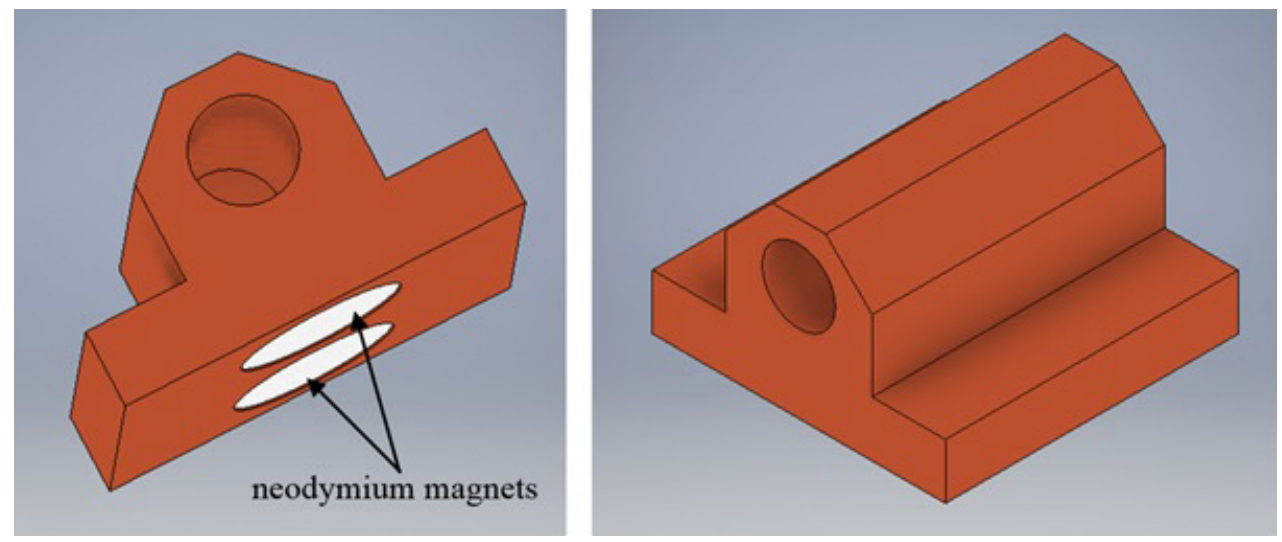

Fig. 8. Model of coper case for temperature sensor 
some kind of thermal insulating material such as styrofoam in order to reduce impact of environment to measurement itself.

The DHT 22 will be placed on the outside part of machine tool as it measures air temperature and humidity. It will be placed in 3D printed case with mounted to machine by screws, doublesided tape, or with magnets. Data from this sensor will be used to eliminate temperature of environment and to correct measured data, what is necessary in order to obtain consistent data.

\section{CONCLUSIONS}

Monitoring system is designed to be used with a training machine tool Emco Concept Mill 105 , but with minor modifications it should be fully compatible with virtually any imaginable machine tool. Mentioned machined tool was selected because it is available for experiments in laboratory of machine tool programing at Department of Automation and Production systems, Faculty of Mechanical Engineering, University of Zilina. Same and similar machines are common at high schools and universities, as they are ideal for industrial training because of their capability to be controlled by various control systems. Monitoring system is designed to be used with training machine tool Emco Concept Mill 105, but with minor modifications it should be fully compatible with virtually any imaginable machine tool. Mentioned machined tool was selected because it is available for experiments in laboratory of machine tool programing at Department of Automation and Production systems, Faculty of Mechanical Engineering, University of Zilina. Same and similar machines are common at high schools and universities, as they are ideal for industrial training because of its capability to be controlled by various control systems. [12]

All sensors tested and described in this article fulfilled our requirements and are fully appropriate to be implemented in monitoring sensor. However, the board selected for initial tests will be probably replaced by faster one as the implementation of real time FFT analysis is planned on board level in order to reduce computing load on computer. Currently, we are working on communication protocol in order to maximize the efficiency of data collection. After that the capabilities of recording of measured data will be implemented to a new version of MT monitor software.
The proposed system should be deployed on multiple machine tools across several schools in order to collect the amount of data necessary to establish values corresponding with normal conditions of machine tools. The next step will be implementing a system of alarms that will be able to identify arising error and warn the operator.

The data from monitoring can be analyzed together with the result of diagnostic measurements, such as determination of machine tool precision, using data mining techniques that can reveal yet unknown correlations of various parameters and thus contribute to the development of new methods of multiparametric diagnostics.

\section{REFERENCES}

1. Císar M.: Diagnosis of equipments. In. Mechanization and automation equipment for processing. Cluj-Napoca: Publishing House Alma Mater, 2015, 209-240.

2. Stuchlý V., Poprocký R.: Údržba strojov a zariadení, 1. vyd. Žilina: Žilinská univerzita, 2013, 359.

3. Čuboňová N., Kuric, I.: Software program for training of control system Sinumerik 840D. Academic Journal of Manufacturing Engineering, 9(3), 2011, 80-83.

4. Čuboňová N., Kuric I.: Data structures implementation of the protocol STEP-NC at CNC machines programming. Komunikacie, 16(3A), 2014, 176-183.

5. Kuric I., Císar M., Novosád M., Krchova D., Grozav S.: Experimental device for practicing routines of machine tool precision measurement. Academic Journal of Manufacturing Engineering. 13(1), 2015, 39-44.

6. Čuboňová N., Císar M.: Design of camera mount and its application for monitoring machining process. Advances in Science and Technology Research Journal, 9(26), 34-40.

7. Analog Devices.: Data Sheet ADXL345. 2009. [Online: http://www.analog.com/media/en/technical-documentation/data-sheets/ADXL345.pdf]

8. Poppeová V., Uríček J., Bulej V., Šindler P.: Development of simulation software and control system for mechanism with hybrid kinematic structure. Joint 41st International Symposium on Robotics and 6th German Conference on Robotics 2010, ISR/ROBOTIK 2010, 2, 1304-1309.

9. Rengevič A., Kumičakova D.: New possibilities of robot arm motion simulation. In. Communications: scientific letters of the University of Žilina, 18(1A), 2016, 81-86. 
10. Kumicakova D., Jakubcik M.: Specialised robotic hand designing and object grasping simulation. Applied Mechanics and Materials, vol. 282, 2013, 90-98.

11. Litvaj I., Stančeková D.: Knowledge management embedment in company, knowledge repositories, knowledge management significance and usage in company. In decision - making. Procedia Economics and Finance, 2015.
12.Rudawska A., Kuczmaszewski J. 2006. Surface free energy of zinc coating after finishing treatment. Materials Science - Poland, 24(4), 975-981

13. Krajcovic M., Bulej V., Sapietova, A. Kuric I.: Intelligent manufacturing systems in cxoncept of digital factory. Komunikacie, 15(2), 2013, 77-87. 